\title{
Occupational Stress: Major Factor for the Loss in Efficiency of an Employee of Bank - A Study
}

\author{
Gracy Pravin Rangari ${ }^{1}$, Dr J N Chakravorty ${ }^{2}$ \\ ${ }^{1}$ Research Scholar, Department of Management, Gondwana University \\ ${ }^{2}$ Principal, Sau. Leena Kishor Mamidwar Institute of Management Studies and Research, Kosara, \\ Chandrapur
}

\begin{abstract}
Employees' working stress is increasing in both public and private sector banks nowadays, particularly in private sector banks. It has been observed that managerial level personnel in the banking sector are overly preoccupied with their work both inside the office (desk job) and outside the office (field job). Because he or she needs to accomplish both family and organisational obligations, stress is developed, resulting in an imbalance in family and work life. Stress is the result of a disagreement between our external environment and ourselves, which causes emotional and physical strain. It is hard to live without stress in today's fastpaced society, whether you are a student or a working adult. Job stress levels of permanent employees in private and public sector banks, according to the findings, public sector bank employees are significantly more stressed than private sector bank employees due to a lack of control over their jobs, lack of social support from managers, and a mechanistic and strict organizational structure.
\end{abstract}

Keywords: Work Stress, Causes of Stress, Types of Stress, Organizational Behaviour

\section{Introduction}

"Stress is often termed as twentieth century syndrome born out of man's race toward modern progress and its ensuring complexities. At one point or the other, everybody suffers from stress. Stress has become a part of day-to-day living of every individual. On the one side, stress provides the means to express talents and energies, and pursue happiness; while on the other it can also cause exhaustion and illness, either physical or psychological"[1]. Every young person's dream in today's society is to work in the banking business. For them, it is a coveted corporate position. Everyone believes that working in banking is both enjoyable and stress-free. However, several national studies have revealed that banking positions, whether in the public or private sector, are stressful. Nowadays, stress management is more crucial in the service, financial, and banking industries. There is no such thing as a job that is stress-free. As they complete the tasks allocated to them, everyone at work is subjected to strain and worry. The banking industry plays an essential part in the development of the country's economy. Banking personnel have a difficult job since they must contact directly with customers at all levels. Long working hours, excessive workloads, incorrect reward systems, lack of job autonomy, organisational culture, role conflict, and other factors all contribute to high levels of stress among bankers, according to this study. The main reason for this stress is a lack of managerial support for staff. Employees can notice a variety of indicators that indicate excessive levels of stress. If these signs are not recognized early on, they can lead to major health issues in employees, such as depression, heart difficulties, diabetes, and so on. Because of significant job stress, bankers' health and personal lives are both harmed. Most employees are unable to spend time at home or with their families.

\section{Literature Review}

S. Katyal M. Jain and B. Dhanda (2011) [2] "Opine that employees working in non-nationalized banks are at a higher level of stress than nationalized bank employees. It also reveals that there is a highly significant difference in job and stress levels of employees working in nationalized and non-nationalized banks."

K. S. Sathyanaraynan et al. (2011) [3] "The authors studied the impact of stress on the IT industry and its remedial measures. The study observed that due to various job-related issues the employees often feel stress in their jobs and a result of this the productive outcome decreases. This is the biggest IT challenge that the 
industry is facing at present and to tackle these issues various stress management programmes have also been incorporated."

Laiba Dar et al (2011) [4] "Expressed their views that in recent years stress has been on the rise across all spheres of life, specifically at the workplace. The chi-square test and t-test were used to test the hypothesis and showed that stress will have subjective effects."

Mohamed Irfann Ismail (2011) [5] "This study was conducted to identify various dimensions of stress which influence employees working in the financial industry, showed in the financial industry intensification and role ambiguity are the main types of stress will influence the financial sector."

Ritu (2013) [6] "The study is an attempt to investigate and to compare the level of job stress and experience stress related problems among managers of the public sector banks and private sector banks in Punjab. Although certain limitations were met with study, every effort has been made to make it much comprehensive. The objective of the study is to ascertain the level of job stress among the managers of public and private sector banks. The study further aims to study the relationship between organisational factors \& stress symptoms, to study the level of stress among male and female managers, to study the role of age in job stress and to study the role of various coping strategies. The results of the study stated that out of total $80(26.67 \%)$ bank managers fall in low stress category, $72(24.00 \%)$ bank managers fall in medium stress category and $148(49.33 \%)$ bank managers fall in high stress category. Thus more than half of the respondents (73.33) were suffered from medium to high degree of stress."

Samartha, Begum, Lokesh (2014) [7] "The study has been partly descriptive and partly diagnostic. The study is based on both primary and secondary data. There are 27 public sector banks and 30 private sector banks in India. The researcher has focused on 3 public sector banks and 3 private sector banks for the purpose of the study. A sample size of 537 respondents was taken for the study of which 411 employees were from public sector banks and 126 employees were from private banks. The Chi square test was used to test the hypothesis that employees of private sector banks experience more stress than public sector bank employees. The test stated that there is no significant difference between public and private sector banks with respect to the level of stress experienced with the demands of the work."

\section{Need of the Study}

Stress has been documented in many areas, companies, and organisations, with disastrous results. The banking business is one such industry that has undergone significant transformations during the previous two decades. The banking industry is the most essential component of every economy's financial sector. Banking is a fast-growing service business nowadays, therefore maintaining a high level of employee morale is critical to effectively and pleasantly dealing with consumers. As a result, the goal of this study article is to identify and provide solutions to specific challenges that bank employees face as a result of job stress.

\section{Objectives}

The following are the precise aims of this study:

1. To investigate the sources of stress among bank personnel.

2. To investigate the impact of stress on bank personnel in both the public and private sectors.

\section{Research Methodology}

In this study, the method chosen to implement and investigate the research was by using quantitative research method. Quantitative research method was a kind of method involving statistic, mathematics and numerical data collected by using questionnaires and also interviews to do the study, analyze the data and come up with the research result or findings.

\section{Results and Findings}


In the table 1, mean scores of public sector bank employees on stress level, role overload, role ambiguity, role conflict, unreasonable groups and political pressure, responsibility for persons, under participation, powerlessness, poor peer relations, intrinsic impoverishment, low status, strenuous working conditions, unprofitability, etc. has been presented.

\begin{tabular}{|l|c|c|c|c|c|}
\hline & & \multicolumn{2}{|c|}{ Public Sector Bank } & \multicolumn{2}{c|}{ Private Sector Bank } \\
\hline Dimensions & $\begin{array}{c}\text { No. of } \\
\text { Respondents }\end{array}$ & $\begin{array}{c}\text { Mean } \\
\text { Score }\end{array}$ & $\begin{array}{c}\text { Standard } \\
\text { Deviation }\end{array}$ & $\begin{array}{c}\text { Mean } \\
\text { Score }\end{array}$ & $\begin{array}{c}\text { Standard } \\
\text { Deviation }\end{array}$ \\
\hline Stress & 50 & 105 & 10.28 & 135 & 30.81 \\
\hline Role Overload & 50 & 11 & 2.06 & 17 & 3.71 \\
\hline Role Ambiguity & 50 & 09 & 1.03 & 12 & 1.92 \\
\hline Role Conflict & 50 & 10 & 1.23 & 12 & 3.49 \\
\hline Under participation & 50 & 09 & 1.64 & 13 & 2.2 \\
\hline Powerlessness & 50 & 08 & 0.96 & 10 & 2.4 \\
\hline Strenuous working conditions & 50 & 04 & 0.98 & 06 & 1.21 \\
\hline
\end{tabular}

Table 1: Stress Level of Banking Sector

On comparing the mean scores of both the categories of employees, it has been observed that the overall occupational stress is higher among the private sector employees as their mean score has been 135 .

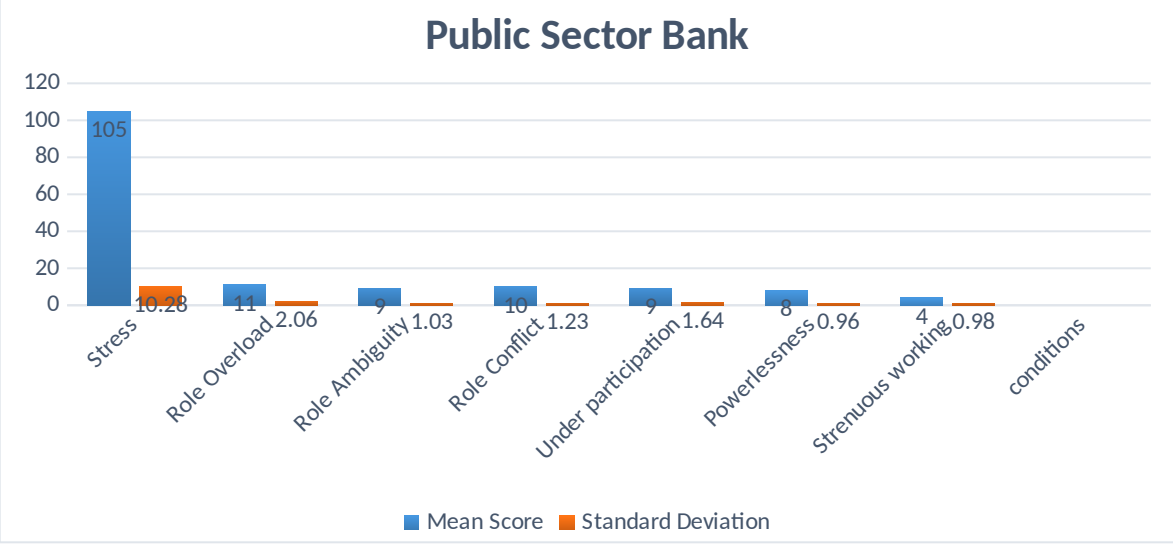

Graph 1: Public Sector Bank Employees Stress Level

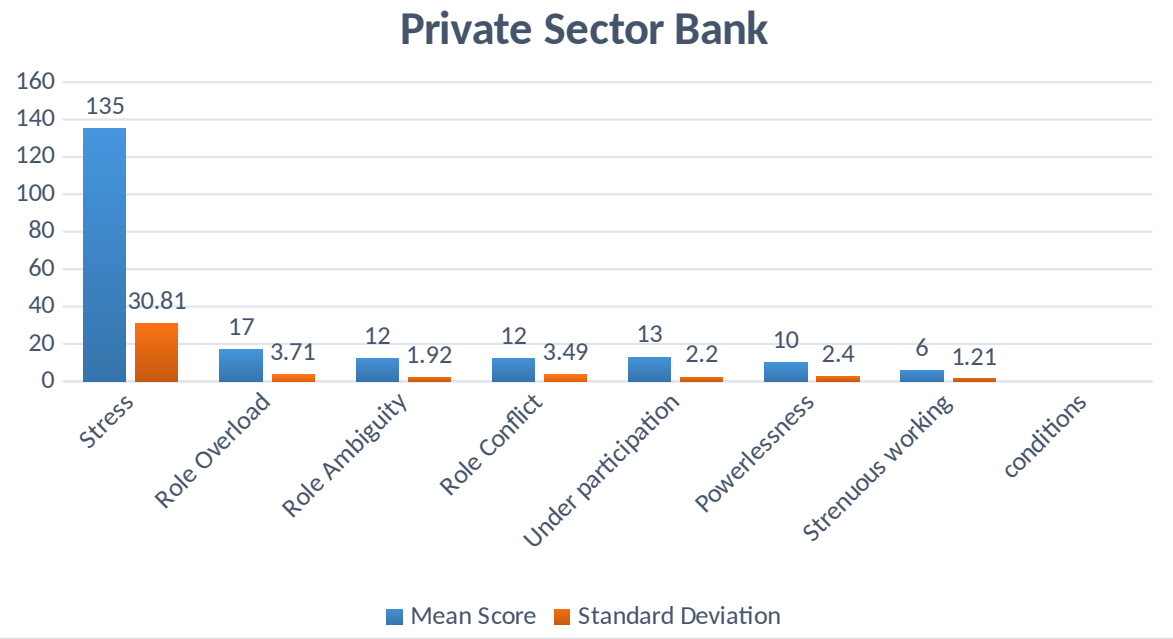

Graph 2: Private Sector Bank Employees Stress Level 


\section{Conclusion}

Stress, according to the findings of this study and a review of the associated literature, is a serious hazard for organisations, affecting not only employee performance but also their health. The nature and qualities of the job cause stress among bank personnel. Work overload, role conflict, communication gaps among colleagues, and comfort with supervisors and coworkers, constant contact with customers, role ambiguity, unpleasant organisational environment, lack of privacy, no career advancement, and target achievement have all contributed to increased employee stress, which has a negative impact on productivity, absenteeism, and worker turnover. Bank staff are inundated with work and have insufficient time to finish it. They find it difficult to balance the demands of their jobs with their personal lives. They strive to strike a balance in their life and frequently alternate between home and work. Flexible work hours could be implemented to boost employee happiness and minimise stress. Individuals have a limited capacity for labour and information processing. Managers are frequently pushed to the limit by increasing workloads and shrinking resources. Workload can be exhausting, and it frequently motivates employees to work far longer hours, resulting in stress, weariness, and burnout.

\section{References}

[1] Enekwe, C. I., Agu, C. I., \& Nnagbogu, E. K., (2014, July). Stress Management Techniques in Banking Sectors in Nigeria. IOSR Journal of Business and Management (IOSR-JBM), 16 (7), Ver. IV, pp. 33 38.

[2] S. Katyal M. Jain and B. Dhanda (2011) A Comparative Study of Job Stress and Type of Personality of Employees Working in Nationalized and Non-nationalized Banks, Kamla-Raj 2011, J Psychology, 2(2): 115-118 (2011).

[3] K. S. Sathyanaraynan \& Dr. K. Maran (2011); A Study on Stress Management in IT Industry, Journal of Management Research \& Development, Vol. 1, No. 1, pp $21-26$.

[4] Laiba Dar,Anum Akmal, Muhammad Akram Naseem,Kashif Ud Din Khan (2011) Impact of Stress on Employees Job Performance in Business Sector of Pakistan, Global Journal of Management and Business Research Volume 11 Issue 6 Version 1.0, ISSN: 0975-5853.

[5] Mohamed Irfann Ismail (2011) Identifying Work-Related Stress among Employees in the Malaysian Financial Sector, World Journal of Management, Vol. 3. No. 2. September 2011 Pp.229-243.

[6] Ritu, (2013). "Job Stress and Coping Behaviour among Managers: A Study of Public and Private Sector Banks in Punjab". Patiala, Punjabi University Patiala.

[7] Samartha, Vishal, Dr., Begum, Mushtiary, Dr., \& Lokesh. (2014). "A comparative analysis of occupational stress among the employees in public and private sector banks in dakshina kannad district". International Journal of Conceptions on Management and Social Sciences Vol. 2, Issue. 2, ISSN: $2357-2787$. 